\title{
Research on the Construction of Public Management Discipline Under the Background of New Liberal Arts
}

\author{
Jianguo Huo* \\ Heilongjiang University, Harbin 150080, Heilongjiang Province, China \\ *Corresponding author: Jianguo Huo, $19835591 @$ qq.com
}

\begin{abstract}
Under the background of new liberal arts, the construction of public management discipline should be based on the social times, the goal of talent cultivation, and the characteristics of the discipline itself, so as to meet the requirements of new liberal arts. In terms of social background, the public management discipline should not only respond to the new problems arising from the technological revolution, but also to the problems of national governance in the new era. In terms of the goal of talent cultivation, the public management discipline should not only cultivate public management professionals but also undertake the basic task of establishing virtue and cultivating talents. In terms of the characteristics of the discipline itself, the public management discipline should highlight the functional advantages of humanistic education, comprehensive discipline, and social service.
\end{abstract}

Keywords: New liberal arts; Public management discipline; Construction; Innovation

Publication date: October 2021; Online publication: October 29, 2021

\section{Introduction}

Since the 18th National Congress of the Communist Party of China (CPC), many new ideas have been put forward in the field of higher education in China under the background of the overall promotion of the national strategy of "double first-class," among which new liberal arts is one of them. At present, new liberal arts has become an important guiding concept of liberal arts construction in higher education. It is an important task to strengthen the construction of public management discipline under the background of new liberal arts. Therefore, discussing the construction of public management discipline under the background of new liberal arts has important value significance for perfecting the system, improving the quality of talent cultivation, and enhancing the social influence of public management.

As a new concept, new liberal arts was first proposed and implemented by Hiram College in the United States in 2017. It mainly refers to the reorganization of traditional liberal arts major and the integration of new technologies into philosophy, literature, language, and other courses to provide comprehensive interdisciplinary learning for students. At present, the construction of new liberal arts advocated by China is mainly based on the innovative development trend of higher education in the new era as well as the transformation and upgrading of traditional liberal arts, so as to innovate the mode of talent cultivation. Compared with traditional liberal arts, there are a few features of new liberal arts that are emphasized.

(1) Incorporation of new technology.

This involves the integration of new technology with liberal arts in thought, content, and application, as well as the exposition of a logical connection between "modern science and technology" and "philosophy and social science." 
(2) Requires new integration.

This involves realizing the integration of humanities with social sciences as well as the integration of social sciences with natural sciences.

(3) Requires the respond to new demands.

This involves building discourse system of philosophy and social sciences with Chinese characteristics and Chinese style based on the reform of the world pattern and China's reform in the new era.

(4) Requires new functions.

This involves leading the social change, national strategy, and industrial development in China today.

Therefore, under the background of new liberal arts, the construction of public management discipline must respond to the new problems of the times, realize the new requirements of talent cultivation, and highlight the advantages of the discipline, so as to ensure the public management discipline adapt to the requirements of new liberal arts construction.

\section{The construction of public management discipline should respond to the new problems of the times}

The new liberal arts is a new mission entrusted by the times. Therefore, the construction of public management discipline should undertake the mission of responding to the new problems of the times under the background of new liberal arts. The public management discipline is a science that studies how the public sector manages social public affairs with the government as the main body. It has a strong sense of time and toward problems. However, the current teaching materials and courses of the discipline are obviously insufficient to respond to the new problems of the times. At present, human society is in an era of great transformation. This age has presented many new, complex, and challenging problems. The public management discipline must respond to these new problems of the times.

On the one hand, the public management discipline should respond to the new problems ushered in by technological revolution. At present, artificial intelligence, mobile internet, big data, genetic engineering, and other new technologies have brought convenience to economic development, social progress, and global governance; however, they have also created new problems. These new challenges and threats to public management are exemplified by global public governance issues pertaining the environment, climate, health, energy, and population; information security and privacy leakage caused by artificial intelligence; traffic rules and order problems as a result of driverless technology; legal and ethical dilemmas caused by genetic engineering technology. These new problems are not simply scientific and technological problems but also deep-seated problems of public management. This requires the public management discipline to respond to these new problems.

On the other hand, the public management discipline should respond to China's national governance problems in the new era. The 3rd Plenary Session of the 18th CPC Central Committee stated that the overall goal of comprehensively deepening reform is to improve and develop the system of socialism with Chinese characteristics as well as modernize China's governance system and capacity. At present, China is in this process, and this provides new knowledge growth points for the public management discipline. They include issues such as "How to handle the relationship between the government and the market?", "How to handle the relationship between the government and the society?", "How to improve the social governance system?", "How to transform government functions?", "How to build a service-oriented government?", and so on.

These new problems of the times should be involved in the construction of new liberal arts in the course of public management discipline. Therefore, the construction of public management discipline should respond to the new problems of the times in terms of its curriculum, teaching materials, teaching contents, 
and scientific research direction in keeping pace with the times.

\section{The construction of public management discipline should realize the new requirements of talent cultivation}

To a certain extent, the introduction of new liberal arts is to solve the problem of "Who to cultivate in the new era?". In essence, new liberal arts should not only cultivate students to be professional talents with professional knowledge and skills, but also to be comprehensive talents with correct life ideals, values, moral cultivation, and code of conduct. Under the background of new liberal arts, the public management discipline should not only cultivate professionals in the new era, but also fulfill the fundamental task of establishing virtue and cultivating talents.

In terms of professional talent cultivation, the public management discipline should cultivate students to master modern public management theories, methods, and techniques; utilize public management basic theories, specialized knowledge, and professional skills; develop public consciousness, public spirit, public responsibility, innovative skills, and pioneering consciousness; in addition, to be able to adapt to social development requirements. Professionals usually engage in management or service work in party and government organs, public institutions, social organizations, and other public sectors. Hence, such professional talents should be equipped with public affairs cognition, policy understanding and analysis, document writing and processing, social investigation and research, interpersonal relationship coordination, organizational communication, public service, emergency management, and other professional skills. In this manner, talents would be able to give full play to their professional skills in the new era of national governance.

In terms of the fundamental task of establishing virtue and cultivating talents for public management, it is necessary to integrate moral education into teaching materials, the curriculum, and classroom teaching. Therefore, it is essential to achieve several goals in the teaching of public management. Firstly, patriotism should be cultivated among students. Patriotic education should be strengthened in professional teaching. Students should be cultivated to enhance their sense of patriotism and political identity with lofty goals and common ideals, so as to build ideological consensus for the realization of the Chinese dream of national prosperity, national rejuvenation, and the happiness of the people. Secondly, the sense of social responsibility should also be cultivated among students. Exquisite egoism should be eradicated in professional teaching. Students should be cultivated to develop a conscious sense of social responsibility and devotion to the cause of socialist modernization. Thirdly, students should be led to cultivate the "Four Matters of Confidence." In the professional teaching of public management, students should be led to develop confidence in "path, theory, system, and culture." For example, cultural confidence can be strengthened by promoting excellent traditional Chinese political culture, administrative culture, and management culture in the teaching.

Therefore, under the background of new liberal arts, the construction of public management discipline should realize the organic integration of professional courses with ideological and political education courses and fulfill the new task of cultivating professionals for the new era as well as the fundamental task of establishing virtue and cultivating talents.

\section{The construction of public management discipline should highlight its own advantages}

The new liberal arts is humanistic, in which its essence is "liberal arts" itself; the education function of liberal arts cannot be covered in the construction of new liberal arts. The new liberal arts is also comprehensive, whereby it does not only embody the intersection and integration of multiple disciplines in the field of philosophy and social sciences, but also the intersection and integration of liberal arts with 
science and engineering. The new liberal arts is strategic. It should meet the strategic needs of national development, serve the needs of economic and social reform, as well as solve important theoretical and practical problems in the ideas of people and norms of behavior. The public management discipline has unique advantages in these aspects, which perfectly fit into the new liberal arts concept. Therefore, the public management discipline should constantly highlight its own advantages in the construction of new liberal arts.

First, the advantages of humanities education in public management discipline should be demonstrated. The highest purpose of life is to produce something immaterial, such as truth, goodness, and beauty ${ }^{[1]}$. Liberal arts bear such a humanistic education function. The public management discipline, belonging to liberal arts, should also actively display its own advantages through humanistic education. Therefore, the public management discipline should explore the path of integration with philosophy, history, art, and other humanities, improve the connotation of liberal arts in the public management discipline, as well as pay attention to the educational function of the cultivation of humanistic spirit. Highlighting the advantages of humanities education in public management discipline can promote the cultivation of students' values, aesthetic consciousness, moral sentiment, responsibility, and other sound personalities. It can also promote cultural inheritance and innovation, improve the level of national soft power construction, as well as enhance the overall competitiveness of the country.

Second, the comprehensiveness of public management discipline should be demonstrated. The comprehensiveness of public management discipline is outstanding, which is mainly reflected in two aspects. On the one hand, it is comprehensive in its disciplinary basis. The public management discipline is a comprehensive subject developed on the basis of drawing lessons from and absorbing the achievements of political science, economics, management science, law, and sociology. The other is the complexity of its managed affairs. The affairs of public management involve governance issues in politics, economy, culture, society, ecology, and other fields as well as complex social public issues that are integrated with a variety of relationships. It can be appreciated that the comprehensiveness of public management discipline ensues a great advantage in the construction of new liberal arts. Therefore, the construction of public management discipline should highlight such comprehensiveness to meet the requirements of the construction of new liberal arts.

Finally, the social service function of public management discipline should be demonstrated. The development of higher education in China should serve the people, the governance of the CPC, the consolidation and development of the socialist system with Chinese characteristics, the reform and openingup, as well as the socialist modernization drive. The public management discipline aims to explore the objective laws contained in the practice of public management as well as construct the organization and system of public management by using the theories and practical experiences of public management, so as to promote social progress and development. The public management discipline has strong applicability. This reflects that the discipline has a strong advantage of social service function. Therefore, under the background of new liberal arts, the construction of public management discipline should strengthen the orientation of "four services," which provide decision-making advisory services, intellectual support, as well as talent guarantee for national and local economic and social development.

\section{Conclusion}

In conclusion, the construction of new liberal arts is a new mission entrusted by the times to higher education and has become an inevitable requirement of talent cultivation and subject convolution development in colleges and universities. It is bound to have a profound impact on the construction of liberal arts. The construction of new liberal arts is both an opportunity and a challenge for the public management discipline. The construction of public management discipline should be based on the 
background of social times, the goal of talent cultivation, and the characteristics of the discipline itself, so as to meet the requirements of new liberal arts. Of course, the construction of public management discipline under the background of new liberal arts is a systematic project. It involves the construction of a curriculum, a teaching material system, teaching methods, practice platforms, teaching staffs, scientific research, rules, and regulations. It is certain that the construction of new liberal arts would promote the systematic reform of public management discipline. It is able to perfect the system of the discipline, improve the quality of talent cultivation of public management, and enhance the social influence of public management discipline.

\section{Funding}

This study was supported by the key project of Heilongjiang Province Education Science "14th Five-Year Plan," The Research on the Professional Integration Construction of Public Management Discipline Under the New Liberal Arts Concept (GJB1421003) and the Higher Education Teaching Reform Research Project of Heilongjiang Provincial Education Department in 2020, Research on Teaching Reform of Administrative Management Specialty Under the Background of New Liberal Arts Construction (SJGY20200546).

\section{Disclosure statement}

The author declares that there is no conflict of interest.

\section{References}

[1] Sarton G, 1937, The History of Science and the New Humanism, Harvard University Press. 